\title{
The Effect of Mother's Perceived Parenting Behaviors on School Adjustment Through Executive Function Difficulty and Anxiety of Children: A Longitudinal Study Using the Auto-Regressive Cross-Lagged Model
}

\author{
Sae-Young Han ${ }^{1}$, Hyun-Ah We ${ }^{2}$, Junghee Lee $^{3}$ \\ Professor, Department of Child Development \& Intervention, Ewha Womans University, Seoul, Korea ${ }^{1}$ \\ Ph. D., Student, Department of Child Development \& Intervention, Ewha Womans University, Seoul, Korea ${ }^{2}$ \\ M. A., Department of Child Development \& Intervention, Ewha Womans University, Seoul, Korea ${ }^{3}$

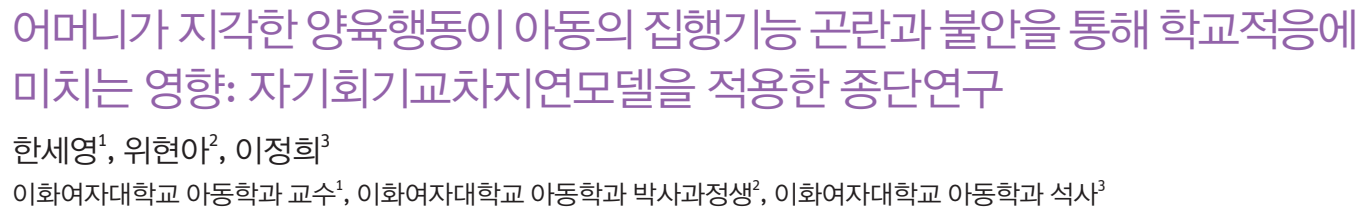

Objectives: This study examined the longitudinal mediation effect of child's executive function difficulty and anxiety in the relationship between mothers' perceived parenting behavior and child's school adjustment. The longitudinal interaction effect between the executive function difficulty and anxiety is also examined.

Methods: For the analyses, data from 2,150 pairs of mothers and their children (817 males, 38.0\%; 781 females, $36.3 \%$ ) who participated in the $8^{\text {th }}$ to $11^{\text {th }}$ Panel Study on Korean Children (PSKC) is used. The survey data were analyzed using structural equation model (SEM) including the autoregressive cross-lagged model with SPSS 21.0 and AMOS 21.0 programs.

Results: First, the child's executive function difficulty had a significant effect on the level of anxiety in the following year, but their anxiety did not have significant effect on their executive function in the following year. Second, there was a significant longitudinal mediating effect of executive function difficulty and anxiety in the relationship between mother's parenting behavior and child's school adjustment.

Conclusion: This study explored the meaningful longitudinal path from mother's percieved parenting to school adjustment including developmental interaction between executive function difficulty and anxiety in childhood. The result of this study may provide basic information for the childhood school adjustment intervention.

Keywords: executive function difficulty, anxiety, school adjustment, parenting, Panel Study on Korean Children

\section{Introduction}

학교적응이란 아동이 학교에 대한 애정을 가지고 학교에서

Corresponding Author: Hyun-Ah We, Ph. D. Student, Department of Child Development, Ewha Womans University, 52, Ewhayeodae-gil, Seodaemungu, Seoul, Korea

E-mail: weclinic1004@naver.com
의 생활에 대해 편안함을 느끼며, 인식, 참여, 수행과 같은 전 반적인 학교생활 영역에서 긍정적인 결과를 나타내는 것으 로(Ladd, Kochenderfer, \& Coleman, 1996), 아동의 우울과 같

(C)The Korean Association of Child Studies

This is an Open Access article distributed under the terms of the Creative Commons Attribution Non-Commercial License (http:// creativecommons.org/licenses/by-nc/4.0) which permits unrestricted noncommercial use, distribution, and reproduction in any medium, provided the original work is properly cited. 
은 내재화 문제 뿐 아니라 반사회적 행동과 같은 외현화 문제 에 영향을 미치는(Choi \& Kim, 2015; J. Y. Lee, Chung, Back, \& Batzolboo, 2014) 중요한 발달적 과업이라 할 수 있다. 특히 학 교는 또래관계와 학업 등 아동기 발달과업의 대부분이 이루어 지는 핵심적인 환경이므로 아동의 건강한 발달과 적응을 지 원하기 위해서는 학교적응을 살펴볼 필요가 있다. 또한 초등 학교 시기의 학교적응은 이후 청소년기의 학교생활에도 영향 을 미치는 등(Y. Lee \& Chung, 2016) 장기적인 영향을 미침에 도 불구하고 학업을 중단하는 초등학생의 비율은 지속적으로 증가하는 추세를 보이고 있어(Ministry of Education \& Korean Educational Development Institute, 2020), 아동기 초기 학교적 응에 영향을 미치는 선행요인을 폭넓게 탐색할 필요성이 더욱 강조된다.

지금까지의 연구들에서 학교적응은 개인의 집행기능, 자 아존중감, 정서적 특성과 같은 개인변인(Goh \& Jeon, 2020; S. Kim, Lee, Choi, \& Lee, 2018; J. Y. Lee, Chung, \& Back, 2014), 부모의 양육행동이나 부모자녀관계와 같은 가족변인(H. Y. $\operatorname{Kim} \& \operatorname{Kim} 2020$; J. Y. Lee et al., 2014), 교사의 지원이나 또래 관계와 같은 학교변인에 의하여 영향을 받는 것으로 알려져 왔다(J. Y. Lee et al., 2014).

특히 학령기 초기의 학교적응은 학업적 발달과업과 함께 더 복잡해진 또래와 교사와의 관계, 새로운 환경에서 발생하 는 다양한 문제해결 등을 요구하며 이를 위해서는 인지적 자 원의 적극적이며 효율적인 발휘가 필요하다. 학교적응과 관 련된 여러 인지적 변인들 중 집행기능은 생각과 행동을 의식 적으로 관리하고 통제하는 능력으로(Friedman et al., 2008), 유 연하게 사고하고, 정보를 정신적으로 갱신 및 조작하며, 목표 와 관련 없는 행동을 억제하고, 스스로를 모니터링하며, 현재 상황에 적절한 행동을 계획하고 적용시키는 작용을 함으로써 (Jurado \& Rosselli, 2007) 보유하고 있는 인지적 자원을 적응적 으로 발휘할 수 있도록 하는 핵심적인 능력이라 할 수 있다. 특 히 집행기능은 개인.가족과 학교변인을 포함하는 예측변인들 중 학교적응에 대한 가장 강력한 예측변인으로 나타나(Goh \& Jeon, 2020) 학교적응에 큰 영향을 미치고 있음을 알 수 있다.

최근의 연구들은 집행기능을 학교적응과 관련된 주요한 인 지적 변인으로 주목하고 있으며, 학교적응에 대한 집행기능의 영향력을 일관적으로 보고하고 있다(H. Y. Kim \& Kim, 2020; Goh \& Jeon, 2020). 즉, 집행기능은 학교적응에 직접적인 영 향을 미치며(Neuenschwander, Röthlisberger, Cimeli, \& Roebers, 2012), 어머니의 양육, 미디어 중독과 학교적응의 관계를 매 개하는 것으로 밝혀지고 있어(H. Y. Kim \& Kim, 2020; Park \&
Noh, 2020) 아동의 학교적응을 직간접적으로 예측하는 강력 한 요인으로 주목받고 있다.

한편 불안은 학교적응을 설명하는 개인 변인으로써 우울, 스트레스 등과 함께 연구되어온 주요한 정서변인 중 하나로, 잠재적인 위협이나 위협에 대한 예측으로 인해 유발되어 회피, 경계 및 각성을 포함한 행동 및 생리적 반응을 동반하는 정신 적인 상태이다(Gross \& Hen, 2004). 불안은 학교적응의 구성요 소인 학교에서의 과업수행이나 유연한 대인관계를 어렵게 하 여 학교적응에 영향을 미치는 것으로 알려져 왔다(S. C. Kim, Jeong, \& Park, 2018; Newbegin \& Owens, 1996). 특히 학령기 초 기는 상대적으로 허용적이며 개인적이던 유치원에서 규칙과 집단생활이 강조되는 초등학교로의 커다란 환경적 변화를 맞 이하는 시기로, 대다수 아동은 유치원과 초등학교 사이의 물리 적 환경, 교육과정 및 일과, 규범에 있어서의 현저한 차이를 경 험하며 적지 않은 긴장과 불안을 경험하게 된다(M. Kim, 2008; La Paro, Pianta, \& Cox, 2000). 이처럼 불안은 학령기 초기 학교 적응과 관련한 주요한 정서 중 하나로, 불안이 이후 학교적응 에 어떠한 영향을 미치는지를 탐색할 필요가 있다.

최근의 연구들은 불안과 집행기능 사이의 유의한 관계를 보고하고 있는데, 선행연구에 따르면 분노나(Shields, Moons, Tewell, \& Yonelinas, 2016) 우울이(Ajilchi \& Nejati, 2017) 집행 기능의 발휘에 유의한 영향을 미치지 못한 것에 비하여 불안 은 일관적으로 집행기능에 유의한 영향을 미치고 있었고, 집 행기능 역시 불안에 유의한 영향력을 나타내고 있었다(Han et al., 2016). 다수의 행동학적 연구와 신경과학 연구들을 통해 정서와 인지가 상호작용할 뿐 아니라 개인의 적응적 기능을 위하여 정서와 인지의 통합적인 작용이 필요하다는 것이 입증 되고 있는 바(Ochsner \& Phelps, 2007), 아동의 학교적응에 영 향을 미치는 개인내적 변인으로써 집행기능과 불안 사이의 상 호작용을 살펴보는 것은 학교적응에 대한 인지와 정서 사이의 통합적인 작용을 밝히는 유익한 시도가 될 것이다.

불안과 집행기능 사이의 유의미한 관계는 지속적으로 보고 되고 있으나, 영향력의 방향성에 대해서는 밝혀진 바가 많지 않다. Eysenck와 Derakshan (2011)은 주의통제이론(attentional control theory)과 신경과학적 증거에 근거하여 불안과 집행기 능은 동일한 뇌의 영역을 활성화시키며, 불안의 활성화는 집행 기능의 발휘에 요구되는 심리적 자원의 활용을 방해한다고 설 명한다. 한편 Hirsch와 Mathews (2012)는 불안한 개인은 불안 을 유발하는 환경적 단서가 없을 때에도 더 낮은 집행기능을 나타냄을 지적하며, 위협적인 단서에 대한 주의편향과 같은 인 지적 요인이 걱정을 유발하는 동시에 주의통제를 방해하여 높 
은 수준의 불안과 걱정을 일으킨다고 주장한다. 이처럼 불안과 집행기능의 관계에서 영향력의 방향성에 대해 각기 다른 경로 가 제안되고 있으나, 관련한 연구는 아직까지 소수에 불과하며 비일관적인 결과를 보고하고 있다(Shields et al., 2016; Zainal \& Newman, 2016). 따라서 불안과 집행기능 사이의 영향력의 방 향성을 탐색할 수 있는 연구의 필요성이 제기된다.

나아가 몇몇 선행연구에서 불안과 집행기능 사이의 종단적 관계가 보고되고 있으나(Han et al., 2016; Zainal \& Newman, 2018), 아직까지 불안과 집행기능 사이의 종단적 관계를 탐색 한 연구는 매우 드물며, 특히 국내에서는 아동의 불안과 집행 기능 사이의 관계를 탐색한 연구를 찾아보기 어렵고 이를 종 단적으로 살펴본 연구는 더욱 찾기 어렵다. 하지만 아동의 발 달과 학교적응을 지원하고 예방적 접근을 하기 위해서 불안, 집행기능과 학교적응 사이의 관계를 종단적으로 밝히는 것은 매우 중요하므로 본 연구에서는 학교적응에 영향을 미치는 불 안과 집행기능 곤란의 종단적 상호관계를 밝히고자 한다.

한편 부모의 양육행동은 아동의 발달에 가장 중요한 환경 중 하나로, 학교적응에 영향을 미치는 대표적인 가족변인으 로 다루어져 왔다. 아동기 초기는 학교에 대한 첫 적응을 시작 하는 시기이며 또래보다 부모의 영향을 강하게 받는 시기이므 로, 학교적응에 영향을 미치는 환경 변인으로서 부모의 양육 을 살펴보는 것은 학교적응과 관련한 개인내적 변인의 발달과 학교적응을 돕기 위한 실질적인 대책을 마련하는 데 필수적인 일이라 할 수 있다.

학교적응에 대한 양육행동의 영향은 지속적으로 보고되어 왔으며, 다수의 연구들에서 양육행동은 학교적응에 직접적으 로 영향을 미치기보다는 아동의 집행기능, 불안 등 아동의 개 인내적 요인을 통해 간접적으로 영향을 미치는 것으로 나타 나고 있다(H. Y. Kim \& Kim, 2020; Silva, Dorso, Azhar, \& Renk, 2007). 또한 양육과 학교적응 사이의 관계를 매개하는 요인으 로써 불안과 집행기능은 모두 양육의 직접적인 영향을 받고 있었는데, 부모가 수용적인 양육을 할 때 아동의 사회불안도 는 낮았고(Chung \& Yuh, 2010) 부모의 과보호적 양육은 아동 의 불안과 정적으로 연관되어 있었다(van Gastel, Legerstee, \& Ferdinand, 2009). 특히 부모의 양육은 양육, 심리적 요인, 아동 의 심리적 요인 중 아동의 집행기능을 가장 잘 예측하는 변인 으로 보고되었고(Kwon \& Kim, 2020), Hackman (2012)은 다른 인지적 기능에 비하여 집행기능의 발달에서 어머니의 민감한 양육이 고유한 영향력을 지닌다고 주장하였다. 즉 부모의 양 육은 아동의 불안과 집행기능의 발달에 영향을 미치는 핵심적 환경으로써, 불안과 집행기능을 통하여 학교적응에 영향을 미
칠 수 있다.

한편 여러 선행연구들은 어머니와 아버지의 양육행동이 자 녀의 발달에 차별적인 영향력을 미치고 있음을 보고하고 있 다. 어머니의 양육행동이 아동의 집행기능이나 불안에 유의한 영향을 미치는 것에 비하여 아버지의 양육행동은 영향을 미치 지 못하였으며(Bögels \& van Melick, 2004; Park \& Noh, 2020), 아버지의 양육행동에 비해 어머니의 양육행동이 학교적응에 더 큰 영향을 미치고 있어( $\mathrm{Im}, 2015)$ 아동의 집행기능과 불안, 학교적응에 어머니가 미치는 영향력이 상대적으로 클 것임을 예상할 수 있다. 따라서 본 연구에서는 어머니가 지각한 양육 행동이 아동의 불안과 집행기능 곤란을 통해 학교적응에 미치 는 영향력을 살펴보고자 한다.

초등학교 입학은 아동뿐 아니라 가족의 양적, 질적 변화를 야기하는 사건으로 $(\mathrm{Ki}, 2020)$ 이 시기 아동에 대한 부모의 양 육행동에도 변화가 나타나기 쉽다. 따라서 본 연구에서는 초 등학교 입학 후 1 학년 시기의 양육행동이 $2,3,4$ 학년 시기 아 동의 불안과 집행기능 곤란과 학교적응에 영향을 미치는 발달 적 경로를 파악하고자 한다.

요약하면, 본 연구에서는 아동기 초기 불안과 집행기능 곤 란이 발달하는 과정을 탐색하여 두 변인 사이의 발달적 경로 를 밝히고자 한다. 더불어 양육이 아동의 불안 및 집행기능 곤 란을 통해 학교적응에 영향을 미치는 종단적 경로를 밝히고 자 한다. 이를 위하여 본 연구에서는 자기회귀교차지연모델 (Auto Regressive Cross-Lagged Modeling [ARCL])에 추가적인 독 립변인과 종속변인을 포함한 모델을 분석한 Bosmans와 Velden (2017)의 연구, Chan, Zhang, Lee와 Hagger (2020)의 연구 등을 참고하여, 불안과 집행기능 곤란 사이의 발달적 상호관계를 검증하기 위한 자기회귀교차지연모델(Auto Regressive CrossLagged modeling [ARCL])에 독립변수인 양육행동과 종속변수 인 학교적응을 추가하는 구조방정식 모형을 사용하였고, 이를 분석하여 양육행동이 불안과 집행기능 곤란을 통해 학교적응 에 대한 간접적인 종단적 영향력을 가지는지를 검증하고자 한 다. 이에 따른 본 연구의 연구문제는 아래와 같다.

\section{연구문제 1}

아동의 집행기능 곤란과 불안의 종단적 상호관계와 그 방향 성은 어떠한가?

\section{연구문제 2}

어머니의 양육행동은 아동의 집행기능 곤란과 불안을 통해 아동의 학교적응에 종단적으로 영향을 미치는가? 


\section{Methods}

\section{연구대상}

육아정책연구소에서 수집한 한국아동패널연구(Panel Study on Korean Childrean [PSKC])의 자료 중 8-11세에 해당하는 8-11 차년도(2015-2018; Time 1-4) 자료의 2,150개 표본을 분석에 활용하였다. 한국아동패널의 조사는 2008년 출생한 신생아를 대상으로 1 차년도 조사가 실시되었으며 매해 아동과 아동을 둘러싼 환경을 추적, 조사하고 있다. 이를 위해 매해 질문지에 기초한 면접타개식 방법을 사용한 일반조사를 실시하며 조사 대상 중 약 $10 \%$ 의 아동들에게는 세 시점에서 각 1 회씩 관찰, 면접, 검사 등의 심층조사가 이루어졌다. 본 연구에서는 8차년 도의 어머니의 양육행동(2015; Time 1), 9-11차년도의 아동의 불안과 집행기능 곤란(2016-2018; Time 2-4), 11차년도의 아동 의 학교적응(2018; Time 4) 자료를 활용하였다.

본 연구대상의 일반적 특성은 다음과 같다. 8차년도를 기준 으로, 아동은 남아 817 (38.0\%)명, 여아 781 (36.3\%)명이었고, 어머니의 학력은 고등학교 졸업 이하 463 (21.5\%)명, 전문대 졸업 435 (20.2\%)명, 대학교 졸업 599 (27.9\%)명, 대학원 졸업 93 (4.3\%)명이었으며, 가정의 가구소득은 400 만원 이하 792 (36.8\%)가구, 401-800만원 714 (33.2\%)가구, 801만원 이상 73 (3.4\%)가구였다. 교사의 성별은 9차년도를 기준으로 남성 142 (6.6\%)명, 여성 787 (36.6\%)명이었다.

\section{연구도구}

\section{어머니의 양육행동}

한국아동패널 8차년도에 사용한 Cho, Lee, Lee와 Kwon (1999) 이 개발한 양육행동 척도를 참고하여 한국아동패널 연구진이 자체 제작한 척도를 사용하였다. 총 12 문항으로 온정적 양육 (6문항)과 통제적 양육(6문항)의 2개 하위요인으로 구성되어 있으며, 통제적 양육은 역채점하였다. 문항의 예를 살펴보면 "아이의 의견을 존중하고 표현할 수 있게 한다.", "나는 아이가 내 말에 순종하도록 한다.”이다. 어머니의 자기보고로 이루어 졌으며, 전혀 그렇지 않다(1점)부터 매우 그렇다(5점)까지의 5 점 Likert 척도로 측정되었다. 점수가 높을수록 어머니가 긍정 적인 양육행동을 하는 것을 의미한다. 내적합치도(Cronbach $\alpha$ )는 양육행동 .63, 온정적 양육 .87, 통제적 양육.76이었다.

\section{아동의 불안}

Goodman (1997)이 개발한 Strengths and Difficulties Questionnaire (SDQ)를 Shin, Ahn, Choi와 Kim (2009)이 한국어로 번역한 것 을 사용하였다. 본 척도는 정서증상(5문항), 또래문제(5문항), 행동문제(5문항), 과잉행동/부주의(5문항), 친사회적 행동(5 문항)의 5 개 하위요인으로 구성되어 있다(총 25 문항). 본 연구 에서는 아동의 불안을 측정하기 위해 정서증상 하위요인 문항 중 "걱정이 많고, 종종 근심스러워 보인다." " "낮선 상황에서는 불안해하거나 안 떨어지려고 하고, 쉽사리 자신감을 잃는다.", “두려움이 많고 무서움을 잘 탄다.”의 세 문항만을 사용하였 다. 선행연구에 따르면, SDQ 중 정서증상은 Child Behavior Checklist (CBCL) 중 불안/우울과 높은 상관을 보였고, 아동 의 불안을 측정하는 Revised Children's Manifest Anxiety Scale (RCMAS)과 Spence Children's Anxiety Scale (SCAS)과도 높은 상관을 보였으며(Di Riso, Bobbio, Chessa, Lis, \& Mazzeschi, 2014; Muris, Meesters, \& van den Berg, 2003) SDQ의 정서증 상을 불안/우울을 측정하기 위한 척도로 사용하거나(Blom, Serlachius, Larsson, Theorell, \& Ingvar, 2010), SDQ의 정서증상 과 $\mathrm{CBCL}$ 의 불안/우울 척도를 하나로 묶어 분석에 사용하기 도 하였다(Shin, Ahn, Choi, \& Kim, 2009). 아동의 불안은 학 급 담임교사에 의해 보고되었으며, 전혀 아니다(1점)부터 매 우 그렇다(3점)까지의 3점 Likert 척도로 측정되었다. 점수가 높을수록 아동의 불안 정도가 높음을 의미하며, 내적합치도 (Cronbach $\alpha$ )는 9차년도 불안 .67, 10차년도 불안 .67, 11차년 도 불안 .66이었다.

\section{아동의 집행기능 곤란}

Song (2014)이 개발해 한국아동패널 $9,10,11$ 차년도에 사용한 집행기능 곤란 척도를 사용하였다. 총 40 문항으로 계획-조직 화(11문항), 행동통제 곤란(11문항), 정서통제 곤란(8문항), 부 주의(10문항)의 4 개 하위요인으로 구성되어 있다. 문항의 예 로는 "무슨 일이든 시작하기를 힘들어 한다.", “스스로 행동을 조절하는 데 어려움이 있다.", "잘 참지 못하고 성질을 낸다.", "해야 할 일을 잘 잊는다."가 있다. 어머니에 의해 보고되었으 며, 전혀 아니다(1점)부터 자주 그렇다(3점)까지의 3점 Likert 척도로 측정되었다. 점수가 높을수록 아동이 경험하는 집행기 능 곤란 정도가 높은 것을 의미한다. 내적합치도(Cronbach $\alpha)$ 는 9차년도의 집행기능 곤란 .94, 계획-조직화 곤란 .89, 행동 통제 곤란 .85, 정서통제 곤란 .91, 부주의 .90, 10차년도의 집 
행기능 곤란 .95 , 계획-조직화 곤란 .89, 행동통제 곤란 .85, 정 서통제 곤란 .92, 부주의 .92, 11차년도의 집행기능 곤란 .95, 계획-조직화 곤란 .90, 행동통제 곤란 .86, 정서통제 곤란 .90, 부주의 .92였다.

\section{아동의 학교적응}

Chi와 Jung (2006)이 개발해, 한국아동패널 11차년도에 사용 한 학교적응 척도를 사용하였다. 총 35 문항으로 학교생활 적 응(11문항), 학교수행 적응(11문항), 또래 적응(8문항), 교사 적응 $(5$ 문항)의 4 개 하위요인으로 구성되어 있다. 문항의 예로 는 “정해진 규칙을 잘 지킨다.", "과제를 잘해오며 준비물을 잘 챙겨온다.", "친구를 잘 도와준다.", "필요로 할 때 선생님께 도 움을 청한다.”가 있다. 문항 중 “수업 중 안절부절 못하고 계속 앉아 있기 힘들어 한다.", "나이에 비해 어리게 행동한다.", “선 생님을 지나치게 어려워하고 두려워한다."는 역채점하였다. 학급 담임교사에 의해 보고되었으며, 전혀 그렇지 않다(1점) 부터 매우 그렇다(5점)까지의 5점 Likert 척도로 측정되었다. 점수가 높을수록 아동의 학교적응 정도가 높음을 의미한다. 내적합치도(Cronbach $\alpha$ )는 학교적응 .97, 학교생활 적응 .96, 학업수행 적응 .95 , 또래 적응 .94 , 교사 적응 .81 이었다.

\section{통제변인: 아동 성별 및 어머니의 학력}

본 연구는 인구사회학적 특성 중 아동의 성별과 어머니의 학 력이 아동의 학교적응에 영향을 미친다는 선행연구 결과를 바 탕으로 아동 성별과 어머니의 학력을 통제변인으로 투입하였 다(Jeung \& Jang, 2009; S. Kim \& Kwak, 2011). 아동은 남아의 경우 1 , 여아의 경우 2 로 코딩하였고, 어머니의 학력은 고등학 교 졸업 이하의 경우 1 , 전문대 졸업의 경우 2 , 대학교 졸업의 경우 3 , 대학원 졸업의 경우 4 로 코딩하여 분석하였다.

\section{연구절차 및 자료 분석}

본 연구에서는 SPSS 21.0 (IBM Co., Armonk, NY) 프로그램 과 AMOS 21.0 (IBM Co., Armonk, NY) 프로그램을 사용하 여 다음과 같은 방법으로 분석하였다. 첫째, 자료의 무응답은 Expectation Maximization (EM) 알고리즘을 사용하여 처리하였 다. 또한, 연구대상의 인구사회학적 특성을 살펴보기 위해 빈 도분석을 실시하였으며, 기초분석으로 인구사회학적 특성에 따라 차이가 있는지 살펴보기 위해 일원분산분석을 실시하였
다. 둘째, 조사도구의 신뢰도를 알아보기 위해 Cronbach $\alpha$ 값 을 산출하였다. 셋째, 변인들의 정규성과 각 변인 간의 상관관 계를 알아보고자 기술통계와 Pearson의 적률상관계수를 산출 하였다. 넷째, 아동 불안과 집행기능 곤란 간의 종단관계를 알 아보기 위해 자기회귀교차지연모형(ARCLM)을 사용하였으 며, 모수추정은 최대우도법(Maximum Likelihood [ML])을 사 용하였다. 자기회귀교차지연모형을 분석하기 위해서는 시간 의 경과에 따른 측정동일성, 경로동일성, 오차공분산동일성 이 성립되어야 하므로(J. Kim, Kim, \& Hong, 2009), 본 연구에 서는 측정동일성, 경로동일성, 오차공분산동일성을 순차적으 로 검증하였다. 주요변인 중 불안은 세 문항을 묶은 측정변인 으로 측정하였기 때문에 측정모형에 포함하지 않았다. 측정동 일성은 시간이 지남에 따라 측정한 변인이 동일한지 확인하는 과정이고, 경로동일성은 한 시점의 잠재변인이 이후 시점의 잠 재변인에 미치는 영향이 시간이 지남에 따라 동일한지 확인하 는 과정으로, 같은 개념을 측정한 잠재변인 간의 자기회귀계수 동일성 검증과 서로 다른 개념을 측정한 잠재변인 간의 교차회 귀계수동일성 검증으로 구성된다. 오차공분산동일성은 동일 한 시점에서 측정된 잠재변인의 오차항 사이의 공분산이 시간 이 지남에 따라 동일한지 확인하는 것이다(J. Kim et al., 2009). 다섯째, 양육행동이 학교적응에 미치는 영향에서 아동 불안과 집행기능 곤란의 매개효과를 검증하기 위해 구조방정식 모형 (Structural Equation Modeling [SEM])을 분석하였다. 모형 적합 도는 적합도 지수인 Tucker-Lewis Index (TLI), Comparative Fit Index (CFI), Root Mean Square Error of Approximation (RMSEA) 로 평가하였다. $\chi^{2}$ 값은 표본의 크기에 민감하다는 한계가 있으 므로(Hong, 2000) 사용하지 않았다. 적합도 지수 중 TLI, CFI의 값은 .90 이상일 때 적합하며(Hong, 2000), RMSEA 값은 .05 이 상일 때 적합하고 .08 이하일 때 양호하다고 볼 수 있다(Browne \& Cudeck, 1992). 또한, 부트스트래핑(bootstrapping) 방법을 사 용하여 간접효과의 유의성을 평가하였다.

\section{Results}

\section{상관분석}

주요변인인 어머니의 양육행동, 아동의 불안, 집행기능 곤란 및 학교적응 간 상관관계를 살펴보면, 양육행동과 11차년도 불안, 양육행동과 학교적응 간 관계를 제외하고는 주요변인들 간에 모두 유의한 상관이 나타났다(Table 1 참조). 


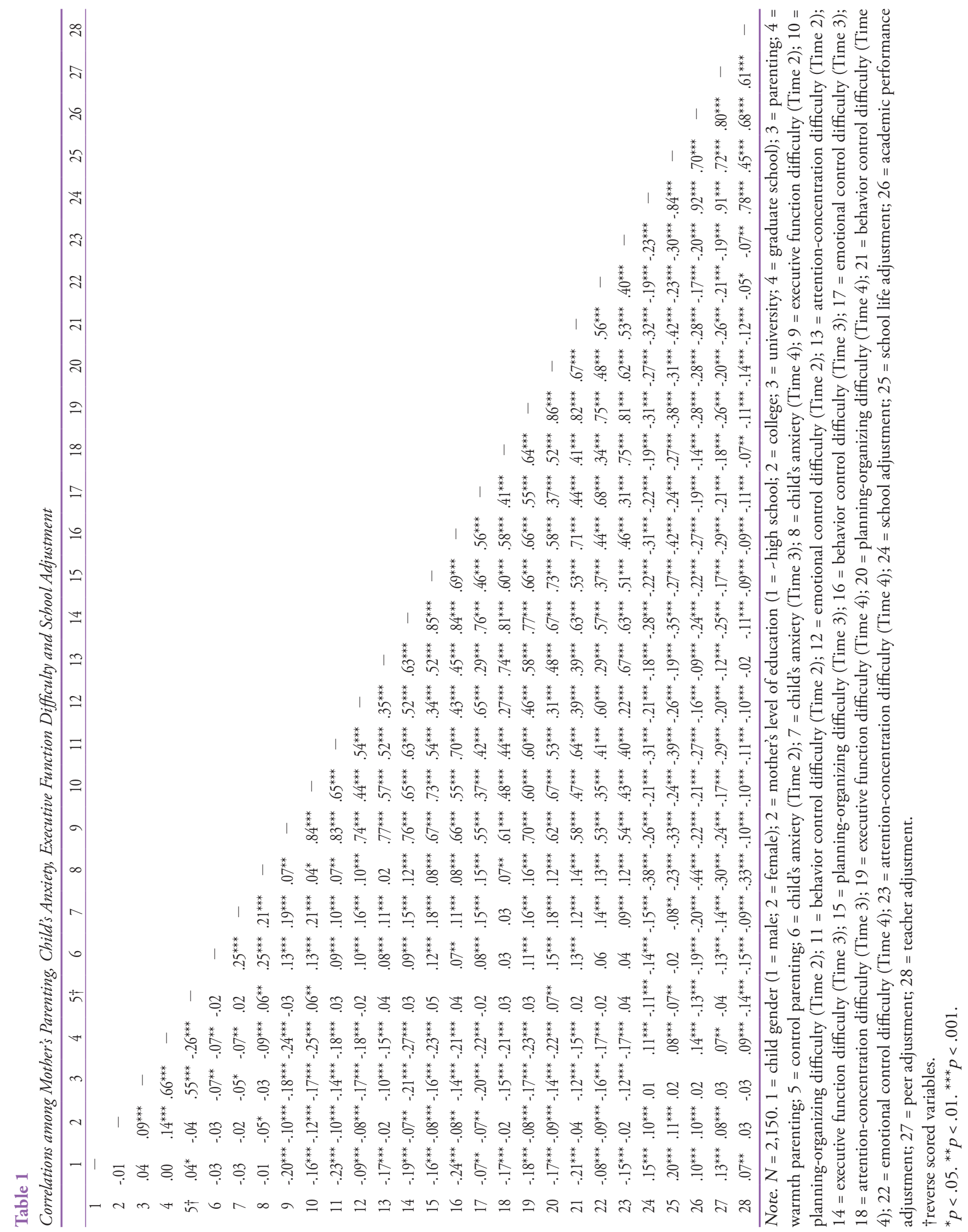




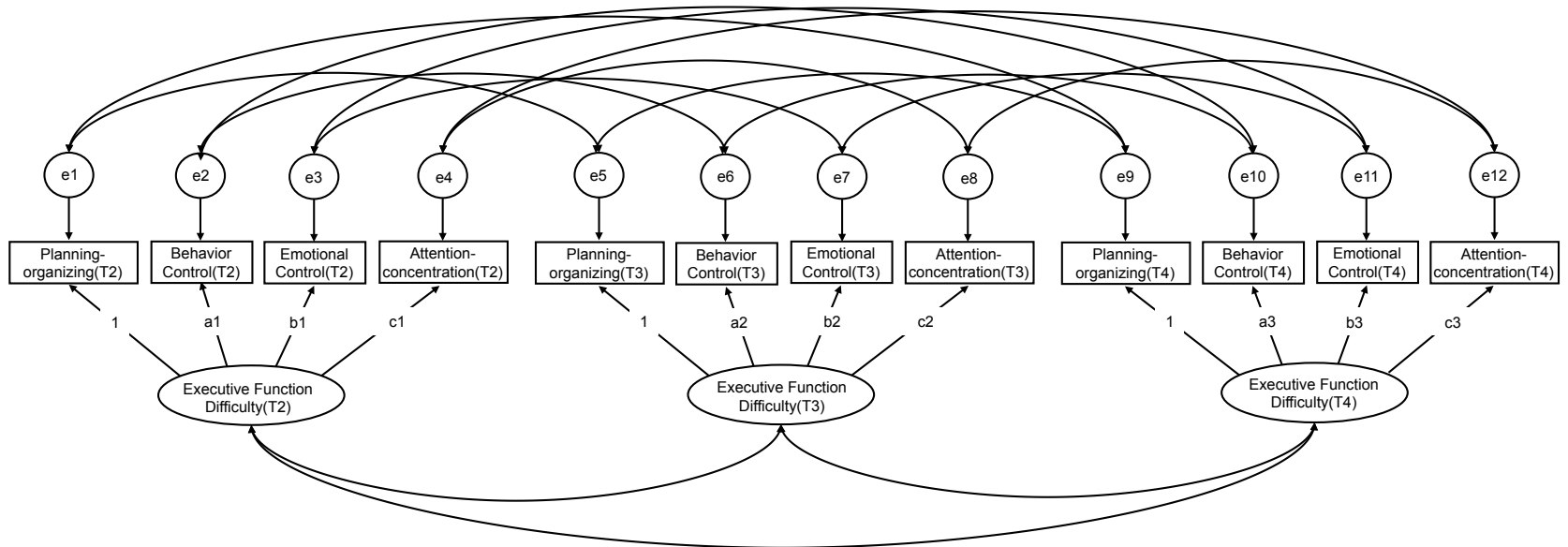

]Figure 1. The measurement model. T2 = Time 2; T3 = Time 3; T4 = Time 4.

Table 2

Model Fit Indices of the Measurement Model

\begin{tabular}{llllc}
\hline \multicolumn{1}{c}{ Model } & TLI & CFI & RMSEA \\
\hline Default model & 1 & .982 & .989 & .050 \\
Measurement invariance & 2 & .981 & .987 & .051 \\
\hline
\end{tabular}

Note. $N=2,150$.

\section{측정모형 분석}

구조모형 검증을 위해 우선적으로 집행기능 곤란이 종단적 측 정동일성을 갖는지 살펴보았다(Figure 1 참조). 횡단자료를 활 용한 확인적 요인분석의 경우 오차항 간 공분산이 허용되지 않지만, 종단자료의 경우 각 시점 별 동일 측정변인의 오차항 간 공분산이 허용되기 때문에 본 모형에서도 오차 간 상관을 설정하였다(Pitts, West, \& Tein, 1996). 잠재변인에 대한 측정변 인의 요인계수를 나타내기 위해 표기된 기호들은 동일화 제약 을 가하기 위해 사용되었다. 예를 들어, a1, a2, a3은 동일한 측 정변인(행동통제 곤란)이 각 시점의 잠재변인(집행기능 곤란) 에 대해 갖는 요인계수가 시간이 지나도 동일하다는 것을 검 증하기 위함이다(Pitts et al., 1996).

모형의 비교는 TLI, CFI, RMSEA를 고려하여 이루어졌다. TLI 값이 .02 이상 작아지지 않았거나 CFI 값이 .01 이상 작아지 지 않았거나 RMSEA 값이 .015 이상 커지지 않았을 때 동일성이 성립되었다고 해석하였다(Chen, 2007). $\chi^{2}$ 차이검증은 표본크기 의 영향을 받는다는 한계가 있기 때문에 이용하지 않았다. 모형 비교 결과, 모형 1 과 모형 2 의 적합도 지수의 차이가 근소하여 Chen (2007)의 기준을 만족하였다 $(\Delta \mathrm{TLI}=.001, \Delta \mathrm{CFI}=.002, \Delta$ $\mathrm{RMSEA}=.001)$. 측정변인의 요인계수에 동일화 제약을 가한 모 형(모형 2)의 적합도는 TLI $=.981, \mathrm{CFI}=.987, \mathrm{RMSEA}=.051$ 로
나타나 적합도 기준을 충족하였다(Table 2 참조).

\section{구조모형 분석}

\section{자기회귀교차지연모형 검증}

아동의 불안과 집행기능 곤란의 시간에 따른 안정성과 상호적 영향 및 두 변인이 아동의 학교적응에 미치는 종단적 영향을 살 펴보기 위하여 자기회귀교차지연모형을 적용하였고(Figure 2 참조), 구조모형에 순차적으로 동일화 제약을 가해 최적의 모 형을 선정하였다(Table 3 참조). 모형의 비교는 측적모형 검증과 마찬가지로 TLI, CFI, RMSEA를 고려하여 이루어졌다. TLI 값 이 .02이상 작아지지 않았거나 CFI 값이 .01 이상 작아지지 않 았거나 RMSEA 값이 .015 이상 커지지 않았을 때 동일성이 성립 되었다고 해석하였다(Chen, 2007). $\chi^{2}$ 차이검증은 표본크기의 영향을 받는다는 한계가 있기 때문에 이용하지 않았다.

모형 1에서 모형 7까지 순차적으로 비교한 결과는 Table 3 과 같다. Table 2에서 측정동일성이 충족되었으므로 경로동일 성의 성립을 확인하기 위해 자기회귀계수에 동일화 제약을 가 한 모형 3 과 모형 4 를 분석한 결과, TLI, CFI 및 RMSEA 값이 동일하여 시간에 따른 자기회귀계수의 경로동일성이 성립되 었다 $(\Delta \mathrm{TLI}=.000, \Delta \mathrm{CFI}=.000, \Delta \mathrm{RMSEA}=.000)$. 


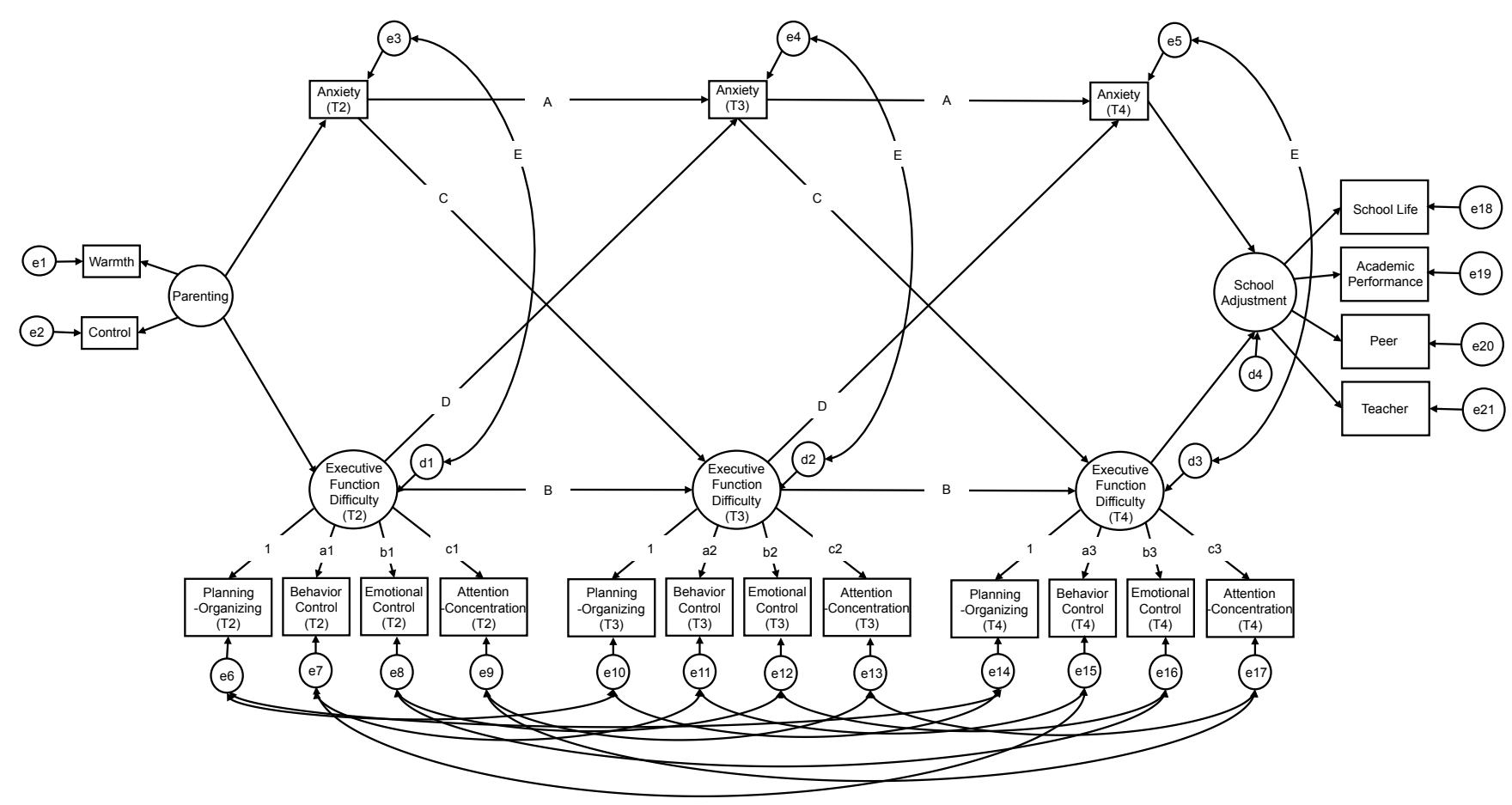

Figure 2. The structural equation model. T2 $=$ Time $2 ; \mathrm{T} 3=$ Time 3 ; $44=$ Time 4.

또한, 교차회귀계수의 경로동일성 가정이 성립되는지 확인 하게 위하여 모형 5 를 분석한 결과, CFI 값과 RMSEA 값은 동 일하였고, TLI 값은 .02 를 초과하지 않아 시간에 따른 교차회 귀계수의 경로동일성이 성립되었다 $(\Delta \mathrm{TLI}=.001, \Delta \mathrm{CFI}=.000$, $\triangle \mathrm{RMSEA}=.000)$. 모형 6을 분석한 결과, TLI 값과 RMSEA 값 은 동일하였고, $\mathrm{CFI}$ 값은 .01을 초과하지 않아 시간에 따른 교 차회귀계수의 경로동일성이 성립되었다 $(\Delta \mathrm{TLI}=.000, \Delta \mathrm{CFI}=$ $.001, \triangle \mathrm{RMSEA}=.000)$.

마지막으로 오차공분산을 동일하게 제약한 모형 7은 TLI, $\mathrm{CFI}$ 및 RMSEA 값이 동일하여 시간에 따른 오차공분산동일성 이 성립되었다 $(\Delta \mathrm{TLI}=.000, \Delta \mathrm{CFI}=.000, \triangle \mathrm{RMSEA}=.000)$. 따 라서 모형 7을 최종모형으로 결정하였다. 모형 7의 적합도는 $\mathrm{TLI}=.917, \mathrm{CFI}=.930, \mathrm{RMSEA}=.065$ 로 나타나 적합도 기준 을 충족하였다.

\section{구조모형 분석 결과}

최종모형으로 결정된 모형 7의 경로계수를 추정하였으며, 그 결과는 Table 4 와 같다. 첫째, 양육행동에서 9차년도 불안 $(\beta=$ $-.08, p<.01), 9$ 차년도 집행기능 곤란 $(\beta=-.32, p<.001)$ 에 미 치는 직접경로는 모두 부적으로 유의하였다. 즉, 어머니가 긍 정적인 양육행동을 할수록 아동의 불안 수준이 높았고 집행
기능 곤란 정도가 증가하였다. 둘째, 9 차년도 불안에서 10 차 년도 불안으로 향하는 직접경로는 정적으로 유의하였고 $(\beta=$ $.20, p<.001), 10$ 차년도 집행기능 곤란으로 향하는 직접경로 는 유의하지 않았다 $(\beta=.02, p>.05)$. 즉, 9 세일 때 불안 정도가 높은 아동은 10 세에도 불안 정도가 높았다. 셋째, 10 차년도 불 안에서 11 차년도 불안으로 향하는 직접경로는 정적으로 유의 하였고 $(\beta=.22, p<.001), 11$ 차년도 집행기능 곤란으로 향하 는 직접경로는 유의하지 않았다 $(\beta=.02, p>.05)$. 즉, 10 세일 때 불안 정도가 높은 아동은 11 세에도 불안 정도가 높았다. 넷 째, 11 차년도 불안이 학교적응에 미치는 직접경로는 부적으 로 유의하였다 $(\beta=-.37, p<.001)$. 즉, 불안 수준이 높은 아동 은 학교적응에 어려움을 느끼는 것으로 나타났다. 다섯째, 9 차 년도 집행기능 곤란이 10 차년도 불안 $(\beta=.11, p<.001)$ 과 10 차 년도 집행기능 $(\beta=.79, p<.001)$ 에 미치는 직접경로는 모두 정 적으로 유의하였다. 즉, 9 세일 때 높은 정도의 집행기능을 겪 는 아동일수록 10 세 때 불안을 많이 느끼고 집행기능 곤란을 더 많이 경험하는 것으로 나타났다. 여섯째, 10 차년도 집행기 능 곤란이 11 차년도 불안 $(\beta=.12, p$ <.001)과 11차년도 집행 기능 $(\beta=.82, p<.001)$ 에 미치는 직접경로는 모두 정적으로 유 의하였다. 즉, 10 세일 때 높은 정도의 집행기능을 겪는 아동일 수록 11 세 때 불안을 많이 느끼고 집행기능 곤란을 더 많이 경 험하는 것으로 나타났다. 일곱째, 집행기능 곤란에서 학교적 
Table 3

The Order of Invariance Test Model

\begin{tabular}{|c|c|c|c|c|c|}
\hline \multicolumn{2}{|r|}{ Model } & Content & TLI & CFI & RMSEA \\
\hline \multicolumn{2}{|l|}{ Default model } & 1 Default model with no constraint & .916 & .933 & .066 \\
\hline \multicolumn{2}{|c|}{ Measurement invariance } & $\begin{array}{l}2 \text { A model in which the factor coefficients }(\mathrm{a} 1, \mathrm{~b} 1, \mathrm{c} 1) \text { for the } \\
\text { measurement variables of executive function difficulties are } \\
\text { equally constrained for each of the three time points }\end{array}$ & .916 & .931 & .065 \\
\hline \multirow[t]{4}{*}{ Path invariance } & $\begin{array}{l}\text { Autoregressive } \\
\text { parameter }\end{array}$ & $\begin{array}{l}3 \text { In addition to Model } 2 \text {, a model in which an identity constraint } \\
\text { is applied to the autoregressive coefficient (A) of anxiety }\end{array}$ & .916 & .931 & .065 \\
\hline & & $\begin{array}{l}4 \text { In addition to model } 3 \text {, a model in which an identity constraint } \\
\text { is applied to the autoregressive coefficient (B) of the latent } \\
\text { variable executive function difficulty }\end{array}$ & .916 & .931 & .065 \\
\hline & Cross-lagged parameter & $\begin{array}{l}5 \text { In addition to model } 4 \text {, a model in which an identity constraints } \\
\text { are applied to the cross regression coefficient }(\mathrm{C}) \text { of anxiety } \\
\text { about the latent variable executive function difficulty }\end{array}$ & .917 & .931 & .065 \\
\hline & & $\begin{array}{l}6 \text { In addition to model } 5 \text {, a model in which an identity constraints } \\
\text { are applied to the cross regression coefficient (D) of the latent } \\
\text { variable executive function difficulty about anxiety }\end{array}$ & .917 & .930 & .065 \\
\hline \multicolumn{2}{|c|}{ Error covariance invariance } & $\begin{array}{l}7 \text { In addition to Model 6, a model in which an identity constraint } \\
\text { is applied to the error covariance (E) between anxiety and the } \\
\text { latent variable executive function difficulty }\end{array}$ & .917 & .930 & .065 \\
\hline
\end{tabular}

Note. $N=2,150$.

Table 4

Path Coefficient for the Final Structural Equation Model

\begin{tabular}{lllllll}
\hline \multicolumn{1}{c}{ Pathway from latent to latent variables } & $B$ & $S E$ & $\beta$ & $C R$ \\
\hline Parenting & $\rightarrow$ & Anxiety (Time 2) & -.06 & .02 & -.08 & $-2.86^{* *}$ \\
Parenting & $\rightarrow$ & Executive function difficulty (Time 2) & -.21 & .04 & -.32 & $-5.35^{* * *}$ \\
Anxiety (Time 2) & $\rightarrow$ & Anxiety (Time 3) & .19 & .01 & .20 & $13.78^{* * *}$ \\
& $\rightarrow$ & Executive function difficulty (Time 3) & .02 & .01 & .02 & 1.93 \\
Anxiety (Time 3) & $\rightarrow$ & Anxiety (Time 4) & .19 & .01 & .22 & $13.78^{* * *}$ \\
& $\rightarrow$ & Executive function difficulty (Time 4) & .02 & .01 & .02 & 1.93 \\
Anxiety (Time 4) & $\rightarrow$ & School adjustment & -.62 & .04 & -.37 & $-17.73^{* * *}$ \\
Executive function difficulty (Time 2) & $\rightarrow$ & Anxiety (Time 3) & .12 & .02 & .11 & $7.05^{* * *}$ \\
& $\rightarrow$ & Executive function difficulty (Time 3) & .82 & .01 & .79 & $72.38^{* * *}$ \\
Executive function difficulty (Time 3) & $\rightarrow$ & Anxiety (Time 4) & .12 & .02 & .12 & $7.05^{* * *}$ \\
Executive function difficulty (Time 4) & $\rightarrow$ & School adjustment & .82 & .01 & .82 & $72.38^{* * *}$ \\
\hline
\end{tabular}

Note. $N=2,150$.

${ }^{* *} p<.01 .{ }^{* * *} p<.001$.

응으로 향하는 직접경로는 부적으로 유의하였다 $(\beta=-.28, p<$ .001). 즉, 집행기능 곤란 정도가 큰 아동일수록 학교적응에 어 려움을 많이 느끼는 것으로 나타났다.

종합적으로 살펴보면, 자기회귀계수를 통해 살펴본 불안과 집행기능 곤란은 모두 9차년도가 10 차년도에 미치는 영향, 10
차년도가 11 차년도에 미치는 영향이 정적으로 유의한 것으로 나타났다. 즉, 불안과 집행기능 곤란은 각각 한 시점에서 높을 때 이후 시점에서도 높은 정도를 보였다. 교차회귀계수를 살 펴보면, 불안이 집행기능 곤란에 미치는 직접경로가 9차년도 에서 10 차년도에 미치는 영향과 10 차년도에서 11 차년도에 미 


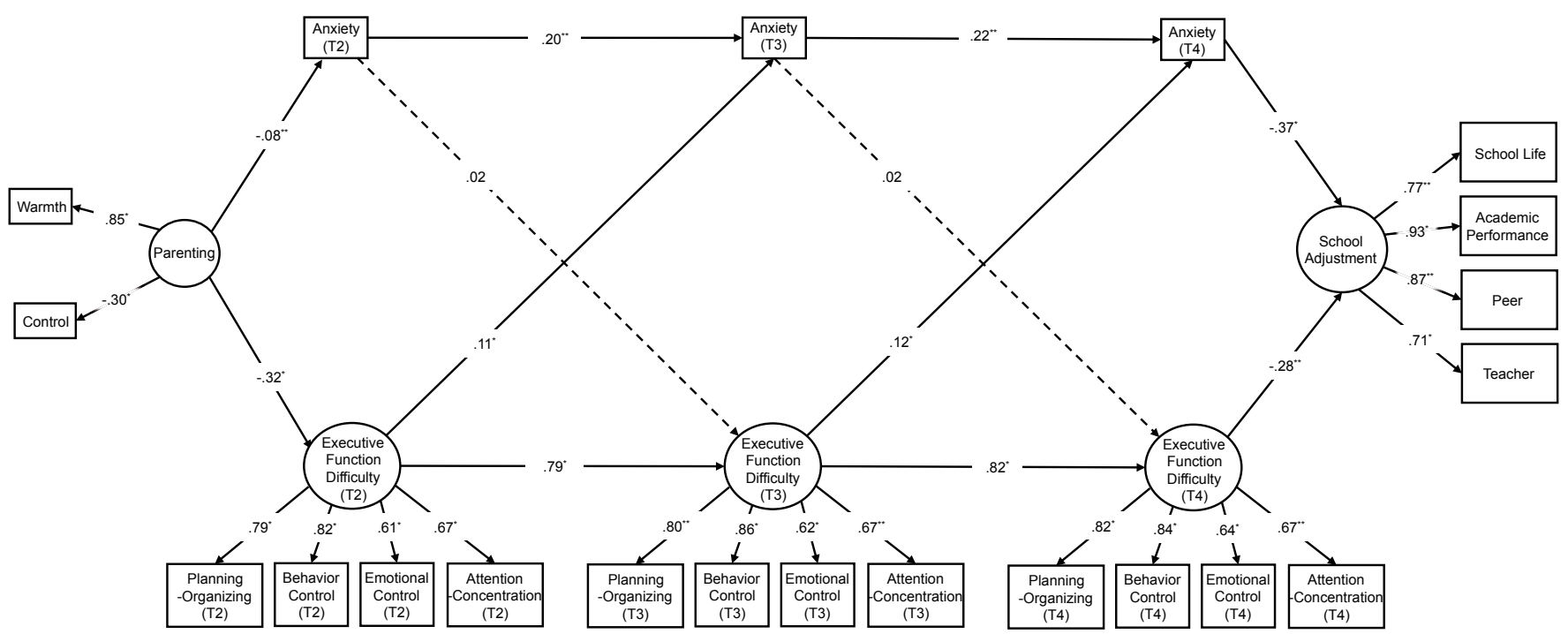

Figure 3. Pathway of the effects of mother's parenting on child's school adjustment through anxiety and executive function difficulty. $\mathrm{T} 2=$ Time 2; $\mathrm{T} 3=$ Time 3; T4 = Time 4.

${ }^{*} p<.05 .{ }^{* *} p<.01$.

Table 5

Direct, Indirect, and Total Effects according to Final Structural Equation Modeling

\begin{tabular}{|c|c|c|c|c|c|c|}
\hline \multirow{2}{*}{\multicolumn{3}{|c|}{ Pathway from latent to latent variables }} & \multicolumn{3}{|c|}{ Standardized path coefficients } & \multirow{3}{*}{$\begin{array}{c}\text { SMC } \\
.01\end{array}$} \\
\hline & & & \multirow{2}{*}{$\begin{array}{l}\text { Direct } \\
-.08^{* *}\end{array}$} & \multirow{2}{*}{$\begin{array}{c}\text { Indirect } \\
-\end{array}$} & \multirow{2}{*}{$\begin{array}{c}\text { Total } \\
-.08^{* *}\end{array}$} & \\
\hline Parenting & $\rightarrow$ & Anxiety (Time 2) & & & & \\
\hline Parenting & $\rightarrow$ & Anxiety (Time 3) & - & $-.05^{* *}$ & $-.05^{* *}$ & .05 \\
\hline Anxiety (Time 2) & $\rightarrow$ & & $.20^{* *}$ & - & $.20^{* *}$ & .05 \\
\hline Executive function difficulty (Time 2) & $\rightarrow$ & & $.11^{*}$ & - & $.11^{*}$ & .05 \\
\hline Parenting & $\rightarrow$ & Anxiety (Time 4) & - & $-.04^{* *}$ & $-.04^{* *}$ & .07 \\
\hline Anxiety (Time 2) & $\rightarrow$ & & - & $.05^{* *}$ & $.05^{* *}$ & .07 \\
\hline Anxiety (Time 3) & $\rightarrow$ & & $.22^{* *}$ & - & $.22^{* *}$ & .07 \\
\hline Executive function difficulty (Time 2) & $\rightarrow$ & & - & $.12^{*}$ & $.12^{*}$ & .07 \\
\hline Executive function difficulty (Time 3) & $\rightarrow$ & & $.12^{*}$ & - & $.12^{*}$ & .07 \\
\hline Parenting & $\rightarrow$ & Executive function difficulty (Time 2) & $-.32^{*}$ & - & $-.32^{*}$ & .16 \\
\hline Parenting & $\rightarrow$ & Executive function difficulty (Time 3) & - & $-.25^{*}$ & $-.25^{*}$ & .66 \\
\hline Anxiety (Time 2) & $\rightarrow$ & & .02 & - & .02 & .66 \\
\hline Executive function difficulty (Time 2) & $\rightarrow$ & & $.79^{*}$ & - & $.79^{*}$ & .66 \\
\hline Parenting & $\rightarrow$ & Executive function difficulty (Time 4) & - & $-.21^{* *}$ & $-.21^{* *}$ & .68 \\
\hline Anxiety (Time 2) & $\rightarrow$ & & - & .02 & .02 & .68 \\
\hline Anxiety (Time 3) & $\rightarrow$ & & .02 & - & .02 & .68 \\
\hline Executive function difficulty (Time 2) & $\rightarrow$ & & - & $.66^{*}$ & $.66^{*}$ & .68 \\
\hline Executive function difficulty (Time 3) & $\rightarrow$ & & $.82^{*}$ & - & $.82^{*}$ & .68 \\
\hline Parenting & & School adjustment & - & $.07^{* *}$ & $.07^{* *}$ & .28 \\
\hline Anxiety (Time 2) & $\rightarrow$ & & - & $-.02^{* *}$ & $-.02^{* *}$ & .28 \\
\hline Anxiety (Time 3) & $\rightarrow$ & & - & $-.09^{* *}$ & $-.09^{* *}$ & .28 \\
\hline Anxiety (Time 4) & $\rightarrow$ & & $-.37^{*}$ & - & $-.37^{*}$ & .28 \\
\hline Executive function difficulty (Time 2) & $\rightarrow$ & & - & $-.23^{* *}$ & $-.23^{* *}$ & .28 \\
\hline Executive function difficulty (Time 3) & $\rightarrow$ & & - & $-.28^{* *}$ & $-.28^{* *}$ & .28 \\
\hline Executive function difficulty (Time 4) & $\rightarrow$ & & $-.28^{* *}$ & - & $-.28^{* *}$ & .28 \\
\hline
\end{tabular}

Note. $N=2,150$. SMC = squared multiple correlation.

${ }^{*} p<.05 .{ }^{* *} p<.01$. 
치는 영향이 모두 유의하지 않은 것으로 나타났다. 한편, 집행 기능 곤란에서 불안으로 향하는 경로는 모두 정적으로 유의하 였다. 즉, 한 시점에서 집행기능 곤란을 많이 경험하는 아동일 수록 이후 시점에서 경험하는 불안 정도가 높은 것을 확인하 였다.

다음으로, 잠재변인 간 구조적 관계를 구체적으로 확인하 기 위하여 양육행동이 불안과 집행기능 곤란을 통하여 학교 적응에 미치는 직간접효과와 총효과를 살펴보았다(Table 5, Figure 3 참조). 간접효과의 유의성을 확인하기 위하여 부트스 트래핑 방법을 사용한 결과, 첫째, 어머니의 양육행동이 10-11 차년도 불안 $(\beta=-.05, \beta=-.04, p<.01)$, 집행기능 곤란 $(\beta=-.25$, $p<.05 ; \beta=-.21, p<.01)$, 학교적응 $(\beta=.07, p<.01)$ 에 미치는 간접효과는 유의하였다. 즉, 한 시점에서의 어머니의 양육행 동은 이후 시점의 아동의 불안, 집행기능 곤란 및 학교적응 정 도에 종단적인 영향을 미치는 것으로 나타났다. 둘째, 학교적 응에 미치는 9-10차 불안 $(\beta=-.02, \beta=-.09, p<.01)$ 과 집행기 능 곤란 $(\beta=-.23, \beta=-.28, p<.01)$ 의 간접효과는 유의하였다. 즉, 한 시점에서 불안과 집행기능 곤란 정도가 큰 아동은 학교 적응에 어려움을 느끼는 것을 확인할 수 있다.

외생변수가 내생변수의 변량을 설명하는 정도를 의미하 는 다중상관자승(Squared Multiple Correlation [SMC])을 살펴 본 결과, 양육행동은 9차년도 불안과 9차년도 집행기능 곤란 을 각각 $1 \%, 16 \%$ 설명하였고, 양육행동, 9 차년도 불안과 집행 기능 곤란은 함께 10 차년도 불안과 집행기능 곤란을 $5 \%, 66 \%$ 설명하였으며, 양육행동, 9-10차년도 불안과 집행기능 곤란은 함께 11 차년도 불안과 집행기능 곤란을 각각 $7 \%, 68 \%$ 설명하 였다. 또한, 양육행동, 9-11차년도 불안과 집행기능 곤란은 함 께 학교적응을 $28 \%$ 설명하는 것으로 나타났다(Table 5 참조).

\section{Discussion}

본 연구에서는 초등학교 1학년 때 어머니가 지각한 양육행동 이 초등학교 2-4학년 시기 아동의 불안과 집행기능 곤란을 통 해 초등학교 4학년 때 아동의 학교적응에 미치는 종단적인 매 개경로를 확인하기 위하여, 한국아동패널 8-11차년도 자료를 사용하여 자기회귀교차지연모형을 포함하는 구조방정식모형 분석을 실시하였다. 본 연구의 주요 결과와 그에 대한 논의는 다음과 같다.

첫째, 아동의 불안과 집행기능 곤란 사이의 자기회귀교차 지연모형을 분석한 결과 아동의 집행기능 곤란은 다음 해 아
동의 불안에 유의한 영향을 미쳤으나 아동의 불안은 다음 해 아동의 집행기능 곤란에 유의한 영향을 미치지 않았다. 이는 인지적 요인에 의하여 걱정, 불안이 발달할 수 있다고 주장한 Hirsch와 Mathews (2012)의 모델을 지지하는 결과로, 집행기 능이 불안에 영향을 미침을 보고한 선행연구들과 일치하는 반 면(Affrunti \& Woodruff-Borden, 2015; Zainal \& Newman, 2018) 불안이 집행기능에 영향을 미친다고 보고한 선행연구들과는 일치하지 않는 결과이다(Shields et al., 2016). 주로 횡단적 관계 를 탐색한 연구에서는 집행기능에 대한 불안의 영향력이 지지 되었고(Billingsley-Marshall et al., 2013; Shields et al., 2016) 종단 적으로 살펴본 연구에서는 불안에 대한 집행기능의 영향력이 지지되었음을 고려할 때(Han et al., 2016; Zainal \& Newman, 2018) 이러한 차이는 종단연구와 횡단연구라는 연구 설계 의 차이에 기인하는 것으로 생각해볼 수 있다. 즉, Eysenck와 Derakshan (2011)의 주의통제이론에서처럼 동일한 시점에서 는 불안이 집행기능의 발휘에 필요한 심리적 자원을 제한하므 로 불안이 집행기능에 영향을 미치는 것으로 나타나지만, 종 단적 관계에서는 집행기능 상의 제약이 부정적 단서에 더 주 의를 기울이게 하거나, 불안을 유발하는 걱정과 같은 사고를 목적에 맞게 중단하고 전환하지 못하게 하여 불안을 지속시 키고 강화시킬 수 있는 것이다. 낮은 집행기능 수행은 동일시 점의 불안과는 유의한 관련이 없었으나 2 년 후의 높은 불안과 관련이 있었고(Han et al., 2016) 집행기능이 9년 후 범불안 장 애의 원거리 원인이 될 수 있음을 보고한 연구들은(Zainal \& Newman, 2018) 종단적 관계에서 집행기능이 불안의 발달에 영향을 미치는 선행요인으로 작용할 수 있음을 시사한다. 하 지만 아직까지 관련한 연구의 수가 절대적으로 부족하며, 종 단연구의 수는 매우 드물기 때문에 추가적인 연구들을 통하여 이러한 주장을 검증할 필요가 있다.

둘째, 어머니의 양육행동이 아동의 집행기능 곤란과 불안 을 통해 학교적응에 간접적으로 영향을 미치는 매개효과가 유 의하게 나타났다. 즉, 초등학교 1학년 때 어머니의 양육행동은 초등학교 $2,3,4$ 학년 때 아동의 집행기능 곤란과 불안을 통해 초등학교 4학년 때 아동의 학교적응에 간접적인 영향을 미쳤 다. 이는 어머니의 양육행동이 아동의 집행기능과(Herbers et al., 2011) 불안을 통해(Silva et al., 2007) 아동의 학교적응에 영 향을 미친다는 선행연구들과 일치하는 결과이다. 즉, 어머니 의 긍정적인 양육행동은 아동의 집행기능 발달과 불안수준을 낮추는 데 기여하여 아동의 학교적응을 돕고 있었다. 또한 초 등학교 1 학년 때의 양육이 3 년 후 학교적응에 장기적 영향을 미치고 있는 바, 학교적응을 위한 지원에 부모에 대한 교육과 
훈련을 포함해야 할 필요성을 시사한다.

또한 불안과 집행기능 곤란은 양육과 학교적응 간의 관계 를 매개하며 학교적응에 직접적인 영향을 미치고 있어, 아동 이 부정적 정서나 신체적 긴장을 경험하지 않으며, 자신의 사 고와 행동을 조절하고 적절히 통제하면서 학교생활을 하는 것 이 학교적응에 중요한 영향을 미침을 알 수 있다. 특히 집행기 능 곤란은 학교적응에 직접적인 영향을 미치는 동시에 불안을 통해 간접적 영향을 미치고 있는 바, 학교적응에 매우 중요한 변인인 것으로 확인되었다. 이러한 결과는 아동의 학교적응 에 집행기능과 불안이 통합적으로 작용하고 있음을 증명하고 있으며, 개인이 자신의 능력을 상황에 적절히 사용하기 위해 서는 인지적 능력과 함께 안정적인 정서가 뒷받침되어야 함을 시사하고 있다. 따라서 아동의 학교적응을 지원하기 위하여 집행기능의 발달을 촉진하는 인지적 접근과 함께 불안을 감소 시키기 위한 정서적 접근을 병행 혹은 통합하여 사용하는 것 이 더욱 효과적인 방법이 될 수 있을 것이다.

본 연구결과들을 종합해보면, 어머니의 바람직한 양육은 아동의 불안과 집행기능 곤란을 감소시켜 학교적응 수준을 높 임을 알 수 있다. 특히 아동의 집행기능 곤란이 높을 경우 다음 해의 불안이 증가하고 있어, 집행기능이 불안과 불안을 통한 학교적응에 영향을 미치고 있는 것으로 나타나 아동의 정서적 안정과 학교적응을 위한 집행기능 발달의 중요성이 강조된다.

본 연구의 제한점과 후속 연구를 위한 제언은 다음과 같다.

첫째, 모든 변인이 단일보고자에 의해 보고되어 평가의 객 관성이 확보되지 못했다는 한계가 있다. 따라서 추후 연구에 서는 어머니의 양육행동을 관찰하거나, 아동의 집행기능이나 불안을 실험과제를 통해 측정하거나, 학교적응의 측정에 아 동, 교사의 보고를 포함하는 등 다양한 방법과 보고자를 포함 하여 연구변인들을 측정할 필요가 있다. 둘째, 본 연구에서는 전반적인 집행기능과 불안 사이의 관계를 살펴보았다. Zainal 과 Newman (2018)에 따르면 집행기능의 하위요인에 따라 불 안에 미치는 영향이 달라지고 있으므로, 추후 연구에서는 불 안에 대한 집행기능의 하위요인별 영향력을 살펴보는 것도 흥 미로울 것이다. 셋째, 본 연구에서는 학령초기 불안과 집행기 능 곤란의 상호작용을 분석하였으나, 추후연구에서는 집행기 능이 활발히 발달하기 시작하는 시기인 유아기를 포함한다면 보다 명확한 발달 경로를 탐색할 수 있을 것이다.

이러한 제한점에도 불구하고, 본 연구는 집행기능 곤란과 불안의 종단적 상호성 검증을 통해 집행기능이 불안의 발달에 영향을 미치는 발달적 경로를 밝혀, 인지적 요인과 정서적 요 인 간의 발달적 상호작용에 대한 이해에 기여하였다. 또한 양
육과 집행기능 곤란, 불안이 학교적응에 영향을 미치는 종단 적 경로를 검증하여 학교적응에 대한 양육의 장기적 영향력과 집행기능 곤란과 불안의 영향력을 밝혔으며 이는 아동의 학교 적응을 위한 효과적인 중재 프로그램을 마련하기 위한 기초자 료로 활용될 수 있을 것이다.

\section{Notes}

This article was presented at the 11th Conference of the Panel Study on Korean Children.

\section{Conflict of Interest}

No potential conflict of interest relevant to this article was reported.

\section{References}

\section{In English}

Affrunti, N. W., \& Woodruff-Borden, J. (2015). The associations of executive function and temperament in a model of risk for childhood anxiety. Journal of Child and Family Studies, 24, 715-724. doi:10.1007/s10826-013-9881-4

Ajilchi, B., \& Nejati, V. (2017). Research paper: Executive functions in students with depression, anxiety, and stress symptoms. Basic and Clinical Neuroscience Journal, 8(3), 223-232. doi:10.18869/nirp.bcn.8.3.223

Billingsley-Marshall, R. L., Basso, M. R., Lund, B. C., Hernandez, E. R., Johnson, C. L.,...Yates, W. R. (2013). Executive function in eating disorders: The role of state anxiety. International Journal of Eating Disorders, 46(4), 316-321. doi:10.1002/eat.22086

Blom, E. C. H., Serlachius, E., Larsson, J.-O., Theorell, T., \& Ingvar, M. (2010). Low Sense of Coherence (SOC) is a mirror of general anxiety and persistent depressive symptoms in adolescent girls-a cross-sectional study of a clinical and a non-clinical cohort. Health and Quality of Life Outcomes, 8(58), 1-13. doi:10.1186/1477-7525-8-58

Bosmans, M. W. G., \& van der Velden, P. G. (2017). Cross-lagged associations between posttraumatic stress symptoms and coping self-efficacy in long-term recovery: A four-wave comparative study. Social Science \& Medicine, 193, 33-40. doi:10.1016/j.socscimed.2017.09.040 
Bögels, S. M., \& van Melick, M. (2004). The relationship between child-report, parent self-report, and partner report of perceived parental rearing behaviors and anxiety in children and parents. Personality and Individual Differences, 37, 1583-1596. doi:10.1016/j.paid.2004.02.014

Browne, M. W., \& Cudeck, R. (1992). Alternative ways of assessing model fit. Sociological Methods \& Research, 21(2), 230-258. doi:10.1177/0049124192021002005

Chan, D. K. C., Zhang, L., Lee, A. S. Y., \& Hagger, M. S. (2020). Reciprocal relations between autonomous motivation from self-determination theory and social cognition constructs from the theory of planned behavior: A cross-lagged panel design in sport injury prevention. Psychology of Sport and Exercise, 48(101660), 1-8. doi:10.1016/j.psychsport.2020.101660

Chen, F. F. (2007). Sensitivity of goodness of fit indexes to lack of measurement invariance. Structural Equation Modeling: A Multidisciplinary Journal, 14(3), 464-504. doi:10.1080/1070 5510701301834

Di Riso, D., Bobbio, A., Chessa, D., Lis, A., \& Mazzeschi, C. (2014). Analysis of the interplay between depression, anxiety, and psychological resources in adolescence using self-report measures. International Journal of Psychiatry in Clinical Practice, 18(2), 103-111. doi:10.3109/13651501.2014.890227

Eysenck, M. W., \& Derakshan, N. (2011). New perspectives in attentional control theory. Personality and Individual Differences, 50(7), 955-960. doi:10.1016/j.paid.2010.08.019

Friedman, N. P., Miyake, A., Young, S. E., De Fries, J. C., Corley, R. P., \& Hewitt, J. K. (2008). Individual differences in executive functions are almost entirely genetic in origin. Journal of Experimental Psychology: General, 137(2), 201225. doi:10.1037/0096-3445.137.2.201

Gross, C., \& Hen, R. (2004). The developmental origins of anxiety. Nature Reviews Neuroscience, 5, 545-552. doi:10.1038/nrn1429

Hackman, D. A. (2012). Socioeconomic status and the development of executive function and stress reactivity: The specific roles of parental nurturance and the home environment (Unpublished doctoral dissertation). University of Pennsylvania, PA.

Han, G., Helm, J., Iucha, C., Zahn-Waxler, C., Hastings, P. D., \& Klimes-Dougan, B. (2016). Are executive functioning deficits concurrently and predictively associated with depressive and anxiety symptoms in adolescents? Journal of Clinical Child \& Adolescent Psychology, 45(1), 44-58. doi:10 $.1080 / 15374416.2015 .1041592$

Herbers, J. E., Cutuli, J. J., Lafavor, T. L., Vrieze, D., Leibel, C., Obradović, J., \& Masten, A. S. (2011). Direct and indirect effects of parenting on the academic functioning of young homeless children. Early Education \& Development, 22(1), 77-104. doi:10.1080/10409280903507261

Hirsch, C. R., \& Mathews, A. (2012). A cognitive model of pathological worry. Behaviour Research and Therapy, 50(10),
636-646. doi:10.1016/j.brat.2012.06.007

Jurado, M. B., \& Rosselli, M. (2007). The elusive nature of executive functions: A review of our current understanding. Neuropsychology Review, 17(3), 213-233. doi:10.1007/ s11065-007-9040-z

Ki, P. (2020). School adjustment and academic performance: Influences of the interaction frequency with mothers versus fathers and the mediating role of parenting behaviours. Early Child Development and Care, 190(7), 1123-1135. doi :10.1080/03004430.2018.1518904

Ladd, G. W., Kochenderfer, B. J., \& Coleman, C. C. (1996). Friendship quality as a predictor of young children's early school adjustment. Child development, 67(3), 1103-1118. doi:10.1111/j.1467-8624.1996.tb01785.x

La Paro, K. M., Pianta, R., \& Cox, M. (2000). Kindergarten teachers' reported use of kindergarten to first grade transition practices. The Elementary School Journal, 101(1), 63-78. doi:10.1086/499659

Muris, P., Meesters, C., \& van den Berg, F. (2003). The Strengths and Difficulties Questionnaire (SDQ): Further evidence for its reliability and validity in a community sample of Dutch children and adolescents. European Child \& Adolescent Psychiatry, 12, 1-8. doi:10.1007/s00787-003-0298-2

Neuenschwander, R., Röthlisberger, M., Cimeli, P., \& Roebers, C. M. (2012). How do different aspects of self-regulation predict successful adaptation to school? Journal of Experimental Child Psychology, 113(3), 353-371. doi:10.1016/j.jecp.2012.07.004

Newbegin, I., \& Owens, A. (1996). Self-esteem and anxiety in secondary school achievement. Journal of Social Behavior and Personality, 11(3), 521-530.

Ochsner, K. N., \& Phelps, E. (2007). Emerging perspectives on emotion-cognition interactions. Trends in Cognitive Sciences, 11(8), 317-318. doi:10.1016/j.tics.2007.06.008

Pitts, S. C., West, S. G., \& Tein, J.-Y. (1996). Longitudinal measurement models in evaluation reserch: Examining stability and change. Evaluation and Program Planning, 19(4), 333-350. doi:10.1016/S0149-7189(96)00027-4

Shields, G. S., Moons, W. G., Tewell, C. A., \& Yonelinas, A. P. (2016). The effect of negative affect on cognition: Anxiety, not anger, impairs executive function. Emotion, 16(6), $792-$ 797. doi: $10.1037 /$ emo0000151

Silva, M., Dorso, E., Azhar, A., \& Renk, K. (2007). The relationship among parenting styles experienced during childhood, anxiety, motivation, and academic success in college students. Journal of College Student Retention: Research, Theory \& Practice, 9(2), 149-167. doi:10.2190/CS.9.2.b

van Gastel, W., Legerstee, J. S., \& Ferdinand, R. F. (2009). The role of perceived parenting in familial aggregation of anxiety disorders in children. Journal of Anxiety Disorders, 23(1), 4653. doi:10.1016/j.janxdis.2008.03.014 
Watts, S. E., \& Weems, C. F. (2006). Associations among selective attention, memory bias, cognitive errors and symptoms of anxiety in youth. Journal of Abnormal Child Psychology, 34, 838-849. doi:10.1007/s10802-006-9066-3

Zainal, N. H., \& Newman, M. G. (2018). Executive function and other cognitive deficits are distal risk factors of generalized anxiety disorder 9 years later. Psychological Medicine, 48(12), 2045-2053. doi:10.1017/S0033291717003579

\section{In Korean}

Chi, S.-A., \& Jung, D.-H. (2006). Validation of school adjustment inventory for first grade elementary school students. Korean Journal of Child Studies, 27(1), 1-15.

Cho, B., Lee, J., Lee, H., \& Kwon, H. (1999). Dimensions and assessment of Korean parenting style. Journal of the Korean Home Economics Association, 37(10), 123-133.

Choi, T.-S., \& Kim, J.-K. (2015). The influence of school adjustment and perceived parental attitude on the depression of school-aged children: The moderating effects of perceived parental attitude. Korean Journal of Youth Studies, 22(12), 595-617.

Chung, M. J., \& Yuh, J. (2010). The effects of perceived parental acceptance on social anxiety and depressive symptoms in children: Examining gender-moderating effects. Journal of the Korean Home Economics Association, 48(9), 103-111.

Goh, E. K., \& Jeon, H. J. (2020). Investigating predictors of first graders' school adjustment in Korean elementary school using latent profile analysis and machine learning. Korean Journal of Child Studies, 41(4), 75-90. doi:10.5723/ kjcs.2020.41.4.75

Hong, S. (2000). The criteria for selecting appropriate fit indices in structural equation modeling and their rationales. The Korean Journal of Clinical Psychology, 19(1), 161-177.

Im, S. (2015). The effects of children's perceptions of positive paternal and maternal parenting behaviors and children's self-efficacy on school age boys' and girls' school adjustment (Master's thesis). Retrieved from http://www.riss.kr/link?id=T13819177

Jeung, Y. M., \& Jang, Y. A. (2009). The effects of home related variables on children's school adjustment. The Korean Society of Community Living Science, 20(1), 91-102.

Kim, M. (2008). An exploratory study of student's experience of transition from kindergarten to first grade. Journal of Educational Studies, 39(1), 181-210.

Kim, H. Y., \& Kim, M. (2020). The effects of maternal parenting behavior on children's school adjustment: The mediating effects of children's media device addiction and executive function difficulty. Korean Journal of Child Studies, 41(1), 105-121. doi:10.5723/kjcs.2020.41.1.105

Kim, J., Kim, M., \& Hong, S. (2009). Gujobangjeongsikmohyeongeuro nonmoonsseugi [구조방정식모형으로 논문 쓰기]. Seoul: Communacationbooks.

Kim, S., Lee, D., Choi, J., \& Lee, D. (2018). Moderating effects of mother attachment and father attachment on the relation between school adjustment, depression, and anxiety in adolescents. Korean Journal of Counseling and Psychotherapy, 30(4), 1301-1326. doi:10.23844/kjcp.2018.11.30.4.1301

Kim, S. C., Jeong, Y., \& Park, H. S. (2018). The influence of perceived parental conflict on the school adjustment of elementary school children: Mediating effect of parenting style, rumination and social anxiety. The Korean Journal of Developmental Psychology, 31(4), 21-41. doi:10.35574/ KJDP.2018.12.31.4.21

Kim, S., \& Kwak, K. (2011). The mediating role of child's temperament on early school adjustment and mother's parenting attitudes: On the negative reactivity of temperament. The Korean Journal of Developmental Psychology, 24(2), 155-171.

Kwon, H., \& Kim, W. (2020). A study of children's executive functioning: Effects of children's, mothers', and fathers' psychological factors, parenting behaviors, and marital satisfaction. Early Childhood Education Research \& Review, 24(1), 143-162. doi:10.32349/ECERR.2020.2.24.1.143

Lee, J. Y., Chung, I. J., \& Back, J. L. (2014). A meta-analysis on the predictor variables of the school adjustment of youth. Korean Journal of Child Studies, 35(2), 1-23. doi:10.5723/ KJCS.2014.35.2.1

Lee, J. Y., Chung, I. J., Back, J., \& Batzolboo, B. (2014). The similarities and differences in predictor variables of youth's prosocial and antisocial behaviors-A meta-analysis-. Journal of the Korean Society of Child Welfare, (47), 125-155.

Lee, Y., \& Chung, H. (2016). A longitudinal study of developmental trajectories and predictors of school adjustment in early adolescence. Studies on Korean Youth, 27(2), 187-214. doi:10.14816/sky.2016.27.2.187

Ministry of Education., \& Korean Educational Development Institute. (2020). Statistical yearbook of education 2020. Retrieved from Korean Education Statistics Service website: https://kess.kedi.re.kr

Panel Study on Korean Children. (2018). Panel study of Korean children 8th-11th survey [Data file and codebook]. Retrieved from https://panel.kicce.re.kr

Park, B., \& Noh, J. U. (2020). Longitudinal effects of parenting behaviors on early school-age children's problem behaviors: Mediating effect of executive function difficulties. Korean Journal of Child Studies, 41(2), 163-179. doi:10.5723/ kjcs.2020.41.2.163

Shin, J., Ahn, J.-S., Choi, Y. H., \& Kim, H.-J. (2009). A clinical usefulness of korean version of Strengths and Difficulties Questionnaire. Korean Journal of Psychosomatic Medicine, 
$17(2), 75-81$.

Song, H. (2014). Validity of child-adolescent self-reported executive function difficulty screening questionnaire. The an Journal of Clinical Psychology, 33(1), 121-137. doi:10.15842/ kjcp.2014.33.1.008

\section{ORCID}

Sae-Young Han https://orcid.org/0000-0001-8207-5927

Hyun-Ah We https://orcid.org/0000-0002-8115-6079

Junghee Lee https://orcid.org/0000-0001-6273-2213

Received December 31, 2020

Revision received February 26, 2021

Accepted April 14, 2021 